\title{
Angiotensin Converting Enzyme Insertion/Deletion Gene Polymorphisms in Sudanese Patients with Chronic Lymphocytic Leukaemia
}

\author{
Aisha M. ADAM ${ }^{1}$, Ibrahim Khidir IBRAHIM ${ }^{1,2}$, Elshazli Widaa ALI ${ }^{1}$, Rosline HASSAN ${ }^{2}$ \\ ${ }^{1}$ Al-Neelain University, Faculty of Medical Laboratory Sciences, Department of Haematology, Khartoum, SUDAN \\ ${ }^{2}$ Universiti Sains Malaysia, School of Medical Sciences, Department of Haematology, Health Campus, \\ Kerian, Kelantan, MALAYSIA
}

\begin{abstract}
The aim of this study was to investigate the association between Angiotensin converting enzyme (ACE) insertion/deletion (I/D) polymorphism and the risk of chronic lymphocytic leukaemia (CLL) in Sudanese patients. We present a case control study that includes 40 Sudanese patients with CLL. Among them, 31 (62\%) were male and 19 (38\%) were female. In addition, 40 subjects who were healthy, were included as a control group. Among them, 19 (47.5\%) male and 21 (52.5\%) female). Molecular analysis showed that the most frequent genotype in CLL patients was I/I, followed by genotypes D/I and D/D. In the control group, D/D was the most frequent genotype, followed by I/D. The I/I genotype was absent. Our data suggested that a significant association was found between ACE I/D polymorphism and CLL among Sudanese patients.
\end{abstract}

Keywords: ACE I/D polymorphism, CLL

\section{INTRODUCTION}

Angiotensin converting enzyme (ACE) plays an important role in the stimulation bone marrow hematopoietic progenitors and umbilical cord blood cells proliferation and differentiation by converting angiotensinogen-I to its physiologically active peptide angiotensin-II which stimulates proliferation and differentiation of hematopoietic stem cells through angiotensin II type 1 receptors. ${ }^{1,2}$

ACE may play a major role in many physiological activities in the body including cellular proliferation and metabolism of various other biologically active peptides owing to broad enzymatic specificity in the body. The gene coding for ACE is local- ized to long arm of the 17th chromosome (17q23.3) and responsible for the production of two isoenzymes somatic and testicular form- according to alternative splicing of the single but duplicated ACE gene. ${ }^{3,4}$ There is a membrane-bound form of ACE which is present on various type of cell, including vascular endothelial cells, epithelial cells, neuronal cells, macrophages and male germinal cells, in which C-domain of the ACE has found to be related to RAS by taking role in conversion of angiotensinI to angiotensin-II and hydroly-ses of bradykinin. ${ }^{5}$ A circulating ACE form also was identified, and it was found to be present in such biological fluids as plasma, amniotic and seminal fluids. 
Differences in the circulating level of ACE between individuals have been determined in part by a polymorphism in the ACE gene which has a chief consequence on the individual phenotype. ${ }^{6}$ The variance of the plasma levels of ACE in the group of healthy subjects was found to be related with An insertion/deletion (I/D) polymorphism located in the intron 16 of the ACE gene. ${ }^{7}$ Moreover, the I/D polymorphism of the ACE gene has been associated to coronary heart disease meanwhile subjects of the DD genotype (homogenous deletion) presented the impress of increasing risk of myocardial infarction. ${ }^{8}$ ACE has also been found in human monocytes/ macrophages, and in the T-lymphocyte population. Thus, ACE like other ectopeptidases, possibly will play a part in the regulation of lymphocyte functions. The T-lymphocyte ACE levels of a specified subject are extremely reproducible when measured on two different times but may vary broadly between individuals in association with I/D polymorphism of the ACE gene. ${ }^{9}$

B cell chronic lymphocytic leukemia (CLL) is the most common type of leukemia in adults in Western countries, and mainly affects elderly individuals. ${ }^{10}$ It is a malignancy of mature clonal B lymphocytes that accumulate in the blood, bone marrow and other lymphoid tissues, and the presence of $\geq 5,000$ clonal B lymphocytes per microliter of peripheral blood persisting for more than 3 months considered positive. ${ }^{11,12}$

In this study, we investigated ACE I/D polymorphisms, which might be a risk factor for CLL. To the best of our knowledge this is the first study exploring the association of ACE (I/D) polymorphisms in Sudan.

\section{MATERIALS and METHODS}

This study is a case-control study, conducted in Khartoum state, Sudan, in the period from April 2016 to April 2017, a total of 40 patients with Chronic Lymphocytic Leukemia and 40 apparently healthy volunteers as a control group were recruited to participate in this study. Patients were obtained at Flow Cytometry Laboratory for Leukemia \& Lymphoma Diagnosis, Khartoum; they were referred for Immunophenotype diagnosis.

Ethical clearance was gotten from the Institutional Review Board at Al Neelain University. Principal investigator obtained written informed consent from all participants prior to their inclusion in the study.

\section{Sample Collection and DNA Isolation}

Four ml of peripheral Blood samples were collected from patients and control- in ethylene diamine tetra acetic acid (EDTA) containing tubes and genomic DNA was extracted by salting out method [13]. To assess the DNA quantification after DNA extraction, we measured DNA by using a NanoDrop spectrophotometer. Then DNA samples were regularly stored at $-20^{\circ}$.

\section{Determination of ACE Genotypes}

The insertion/deletion genotyping was done by polymerase chain reaction (PCR), according to $\mathrm{Ri}-$ gat et al ${ }^{14}$, modified by Ueda et al. ${ }^{15}$ PCR amplification was carried out in $25 \mu 1$ reactions containing three microliter $(\mu \mathrm{l})$ of DNA, $1 \mu 1$ of each primer (Primers shown in Table 1), $4 \mu 1$ Matser mix (GoTaq ${ }^{\circledR}$ Green Master Mix, Promega, USA) and $10 \mu 1$ of nuclease free water.

\begin{tabular}{|c|c|c|c|c|}
\hline \multirow[t]{2}{*}{ Primer direction } & \multirow[t]{2}{*}{ Primer Sequence } & \multicolumn{3}{|c|}{ Product Size } \\
\hline & & DD & II & DI \\
\hline Forward & 5'-CTGGAGACCACTCCCATCCПТСТ-3' & & & \\
\hline Reverse & 5'-GATGTGGCCATCACATTCGTCAGAT-3' & $190 \mathrm{bp}$ & 490bp & $190 \mathrm{bp}$ \\
\hline Internal & 5'-TGGGATTACAGGCGTGATACAG-3' & & & 490bp \\
\hline
\end{tabular}




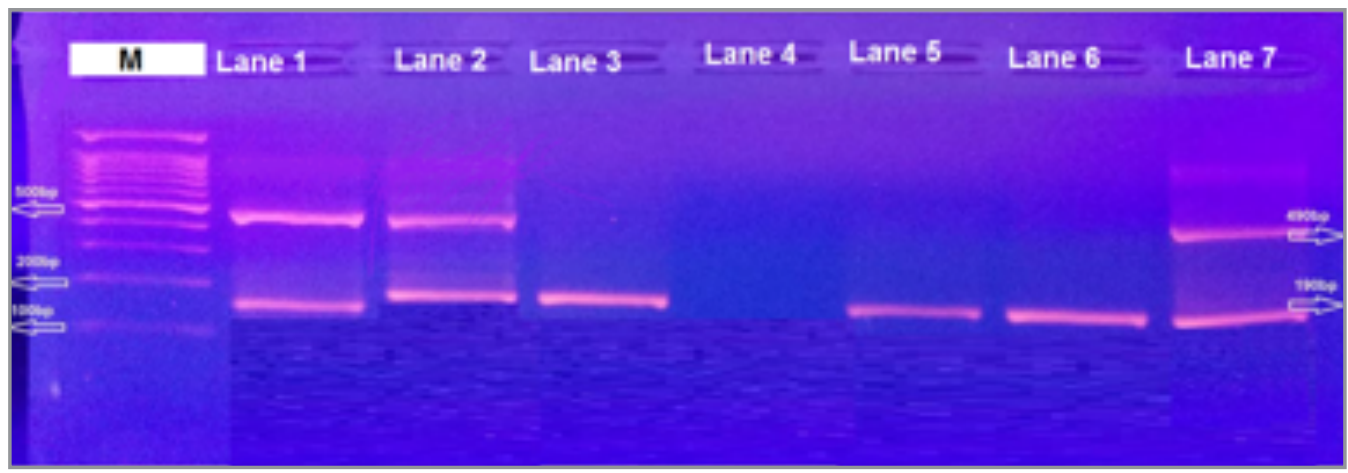

Figure 1. The gel image with different size of bands; Lane M: DNA ladder with 100 bp, Lane1,2,7: ACE genotype (ID) with PCR products 490 and 190 bp, Lane 3, 5, 6 : ACE genotype (DD) with PCR products 190 bp , Lane 4 Negative control.

Thermal cycling conditions were as follows: an initial denaturation step at $95^{\circ} \mathrm{C}$ for $5 \mathrm{~min}, 30$ cycles at $94^{\circ} \mathrm{C}$ for $30 \mathrm{~s}, 52^{\circ} \mathrm{C}$ for $30 \mathrm{~s}$ and $72^{\circ} \mathrm{C}$ for $30 \mathrm{~s}$, and a final extension step at $72^{\circ} \mathrm{C}$ for $10 \mathrm{~min}$. After amplification, PCR products and 100 bp DNA ladder (iNtRON BIOTECHNOLOGY, KOREA), were run on $2 \%$ agarose gel containing ethidium bromide and identified under UV transilluminator using gel documentation system (SYNGENE, JAPAN). Subjects with DD genotype were recognized by the presence of a single $190 \mathrm{bp}$ PCR product. The homozygous genotype for the I allele (II genotype) was recognized by the presence of a 490 bp PCR product. Subjects with the ID genotype is recognized by the presence of both 190 and 490 bp PCR product (Figure 1).

\section{Statistical Evaluation}

Data was collected by structured interview questionnaire and from patients' medical files and analyzed by statistical package for social sciences (SPSS), version 21.
Frequency of different genotypes was calculated, and correlation of genotypes with study groups was tested by Chi-square test. The Hardy-Weinberg equilibrium was tested by goodness of fit $\mathrm{X} 2$ test to compare the observed genotypic frequencies in normal individual to the expected genotypic frequencies, and then calculated from the observed allelic frequencies. A P-value $<0.05$ was considered significance.

\section{RESULTS}

We present a case-control study that includes $40 \mathrm{Su}-$ danese patients with CLL. Among them, 31 (62\%) were male and 19 (38\%) were female. In addition, 40 appernately healthy subjects, were included as a control group. Between them, 19 (47.5\%) male and $21(52.5 \%)$ female).

Molecular analysis showed that the most frequent genotype in CLL patients was I/I, followed by genotypes D/I and D/D. In the control group, D/D was the most frequent genotype, followed by I/D. The $\mathrm{I} / \mathrm{I}$ genotype was completely inattentive (Table 2).

\begin{tabular}{|c|c|c|c|c|c|}
\hline \multirow[t]{2}{*}{ Group } & & \multirow[b]{2}{*}{ I/I } & \multicolumn{2}{|c|}{ ACE Genotype } & \multirow[t]{2}{*}{ Total } \\
\hline & & & I/D & DD & \\
\hline \multirow[t]{2}{*}{ Patient } & $\mathrm{N}$ & 17 & 15 & 8 & 40 \\
\hline & $\%$ & $42.5 \%$ & $37.5 \%$ & $20 \%$ & $100 \%$ \\
\hline \multirow[t]{2}{*}{ Control } & $\mathrm{N}$ & 0 & 8 & 32 & 40 \\
\hline & $\%$ & (0\%) & (20\%) & (80\%) & $100 \%$ \\
\hline
\end{tabular}


The frequencies of the $\mathrm{D}$ allele were 0.61 and 0.90 in patients with CLL and the control group, respectively, while those of the I allele were 0.39 and 0.10 in patients with CLL and the control group, respectively. A significant deviation from the Hardy-Weinberg equilibrium was observed in patients with $\operatorname{CLL}\left(\chi^{2}=1.7, \mathrm{df}=2, \mathrm{p}=0.001\right)$.

The results showed, no statistically significant association between each of ACE I/D genotypes and patients' gender $(\mathrm{p}=0.4)$

This is the first study indicating the possible effects of ACE I/D gene polymorphism on the risk of CLL in the Sudanese population.

\section{DISCUSSION}

We investigated the ACE I/D polymorphism gene coding for polymerase chain reactions in patients with CLL. To the best of our knowledge, our study is the first to provide evidence that the ACE ID/II genotypes may be associated with the development of leukaemia.

The results showed that the DD genotype was the most common among patients with CLL and the control group, followed by the ID genotype. However, the II genotype was present in patients with CLL and completely absent from the control group. Conversely, we found that the frequency of the ID/ II genotype was significantly higher in patients with CLL at $80 \%$ compared with the control group at $20 \%$. A substantial association was found between the I allele (ID or II) of the ACE gene and CLL.

Our study is the first to stated that the II/ID genotypes are noticeably higher in patients compared to the control group and it is associated with CLL in the Sudanese population. This result reach agreement with the finding of AKALIN I et al [8] that the II/ID genotypes are associated with an increased risk of leukemic haematopoiesis also their results presented that $80.4 \%$ of the patients represented ID/ II genotype, whereas it was $55.9 \%$ of the control group and 3.2-fold increased disease risk in the existence of insertion allele (ID/II).

The fact that the angiotensin II genotype stimulates the proliferation of bone marrow hematopoietic progenitors and umbilical cord blood cells suste- nance our finding that the occurrence of the I allele rises the hazard of disease. However, studies that detected the association between ACE I/D gene polymorphism and non-haematological malignancies stated inconsistent results.

Studies examined the association between ACE I/D gene polymorphism and non- hematological malignancies stated conflict results. A study by Gonzalez et al revealed that the subjects with DD genotype had a significantly increased risk of breast cancer development when compared with those caring the II genotype. ${ }^{16}$ Sun et al presented that there was no significant difference in genotype distribution (DD, ID or II) between breast cancer patients and controls. ${ }^{17}$ A study conducted by Hibi et al reported that there is no significant association between the ACE I/D polymorphism and the risk of gastric cancer. ${ }^{18}$ A current study by Cheng did not report any association between the ACE gene I/D polymorphism and lung cancer in either genotype or allele distribution. ${ }^{19}$

This is the first study demonstrating possible effects of ACE I/D gene polymorphism on the risk of CLL in the Sudanese population, this finding is consistent with that reported by AKALIN I et al [8] which concluded that their study is the first study indicating possible effects of ACE I/D gene polymorphism of the local bone marrow RAS components on leukemic hematopoiesis.

The dissimilarities in findings of studies addressing the role of ACE I/D gene polymorphism in development of malignancies may reflect dissimilarities in carcinogenesis process in different types of cancer predominantly between solid tumors and hematological malignancies. ${ }^{20}$

\section{Conclusion}

In conclusion, a significant association was found between ACE I/D polymorphism and CLL among Sudanese patients.

\section{REFERENCES}

1. Strawn WB, Richmond RS, Ann Tallant E, et al. Reninangiotensin system expression in rat bone marrow haematopoietic and stromal cells. Br J Haematol 126: 120-126, 2004. 
2. Abali $\mathrm{H}$, Haznedaroglu IC, Goker $\mathrm{H}$, et al. Circulating and local bone marrow renin-angiotensin system in leukemic hematopoiesis: preliminary evidences. Hematology 7: 75-82, 2002.

3. Soubrier F, Alhenc-Gelas F, Hubert C, et al. Two puta-tive active centers in human angiotensin I-converting enzyme revealed by molecular cloning. Proc Natl Acad Sci USA 85: 9386-9390, 1988.

4. Hubert C, Houot AM, Corvol P, Soubrier F. Structure of the angiotensin I-converting enzyme gene. Two al-ternate promoters correspond to evolutionary steps of a duplicated gene. J Biol Chem 266: 15377-15383, 1991.

5. Coates D. The angiotensin converting enzyme (ACE). Int J Biochem Cell Biol 35: 769-773, 2003.

6. Rigat B, Hubert C, Alhenc-Gelas F, et al. An inserti-on/deletion polymorphism in the angiotensin I-conver-ting enzyme gene accounting for half the variance of serum enzyme levels. J Clin Invest 86: 1343-1346, 1990.

7. Cambien F, Poirier $\mathrm{O}$, Lecerf $\mathrm{L}$, et al. Deletion poly-morphism in the gene for angiotensin-converting enzy-me is a potent risk factor for myocardial infarction. Na-ture 359: 641-644, 1992.

8. Akalin I, Koca E, Karabulut HG, et al. Angiotensin Converting Enzyme Insertion/Deletion Gene Polymorphisms in Leukemic Hematopoiesis. UHOD 21: 1-9, 2011.

9. Elter T, Hallek M, Engert A. Fludarabine in chronic lymphocytic leukaemia. Expert Opin Pharmacother 7: 1641-1651, 2006.

10. Chiorazzi N, Rai KR, Ferrarini M: Chronic Lymphocytic Leukemia. N Engl J Med 352: 804-815, 2005.

11. Hallek M, Cheson BD, Catovsky D, et al. Guidelines for the diagnosis and treatment of chronic lymphocytic leukemia: a report from the International Workshop on Chronic Lymphocytic Leukemia updating the National Cancer Institute-Working Group 1996 guidelines. Blood 111: 5446-5456, 2008.

12. Hallek M. Chronic lymphocytic leukemia: 2017 update on diagnosis, risk stratification, and treatment. American journal of hematology 92: 946-965, 2017.

13. Miller S, Dykes D, Polesky H. A simple salting out procedure for extracting DNA from human nucleated cells. Nucleic Acids Res 16:1215, 1988
14. Rigat B, Hubert C, Corvol P, et al. PCR detection of the polymorphism of the human angiotensin converting enzyme gene (DCP1 (dipeptidyl carboxypeptidase 1) Nucl Ac Res 20: 1433, 1992.

15. Ueda S, Heeley RP, Lees KR, et al. Mistyping of the human angiotensinconverting enzyme gene polymorphism: frequency, causes and possible methods to avoid errors in typing. $J$ Mol Endoc 17: 27-30, 1992.

16. Gonzalez ZLAM, Va'squez AA, Sayed-Tabatabaei FA. et al. Angiotensin-converting enzyme gene insertion/deletion polymorphism and breast cancer risk. Epil Bio Prev 14: 21432145,2005

17. Sun M, Liu C, Wei F, et al. Association of angiotensin I converting enzyme insertion/deletion polymorphism with breast cancer: a meta-analysis, J Renin Angiotensin Aldosteron Sys 12: 611-616, 2011.

18. Hibi $S$, Goto $Y$, Ando T, et al. No Association Between Agiotensin I Converting Enzyme (ACE) I/D Polymorphism and Gastric Cancer Risk Among Japanese. Nagoya J Med Sci 73: 169-175, 2011

19. Cheng Z, Ma R, Tan W, et al. Lack of association between ACE insertion/deletion polymorphism and lung cancer: A meta-analysis. J the Ren-Angio-Aldos Sys 16: 453-458, 2015.

20. Elmubarak, RA, Babiker EA, Ali EW. Angiotensin Converting Enzyme 1/D Polymorphism and Risk of Acute Myeloid Leukemia among Sudanese Population. Lab Med J 2: 10-14, 2016.

\section{Correspondence}

Dr. Ibrahim Khidir IBRAHIM

Universiti Sains Malaysia, School of Medical Sciences, Department of Haematology, Health Campus, 16150 Kubang Kerian, KELANTAN / MALAYSIA

Tel: +60-17-2747814

e-mail: Ibrahimkh81@usm.my 